\title{
ANALYSIS OF MAN-MAN-MACHINE INTERACTION IN COMPLEX VIRTUAL ENVIRONMENT IN CONTEXT OF PSYCHOPHYSICAL STATE
}

\author{
Adam GAŁUSZKA ${ }^{1}$, Anita GAŁUSZKA ${ }^{2}$, Eryka PROBIERZ ${ }^{3}$, Damian BERESKA $^{4}$ \\ ${ }^{1}$ Institute of Automatic Control, Silesian University of Technology, Gliwice, Poland; adam.galuszka@polsl.pl, \\ ORCID: 0000-0002-6176-0500 \\ ${ }^{2}$ Katowice School of Economics, Katowice, Poland; anita.galuszka@gwsh.pl, \\ ORCID: 0000-0002-0030-5360 \\ ${ }^{3}$ Institute of Psychology, University of Silesia, Katowice, Poland; erykaprobierz@gmail.com; Institute of \\ Automatic Control, Silesian University of Technology, Gliwice, Poland, eryka.probierz@polsl.pl, \\ ORCID: 0000-0002-6588-1975 \\ ${ }^{4}$ Institute of Automatic Control, Silesian University of Technology, Gliwice, Poland; damian.bereska@polsl.pl, \\ ORCID: 0000-0003-1110-8212 \\ * Correspondence author
}

Purpose: The aim of the article is to propose the studies and analyses schema considering the psychophysical state of the simulator's users. Within the project a simulator and a virtual environment that allow a group of people (e.g. security guard officers) with real equipment such as cars to train different scenarios are built. The simulator users are interacting both with other colleagues and virtual surroundings. It implies that classical methods of so-called simulator sickness measurement should be adopted to the type of interaction that we call man-manmachine interaction.

Design/methodology/approach: Simulator sickness that manifests itself in physiological ailments is considered in an interdisciplinary approach with particular emphasis on psychological aspects such as coping with stress, anxiety or cognitive and visual techniques related to the combined static and dynamic platforms. The main methods for the research are psychological Paper-and-Pencil surveys, eye-tracking technics, postural equilibrium tests, Poppelreuter test and Simulator Sickness Questionnaire.

Findings: The result is studies and analyses schema related to the simulator users' psychophysical state appearing in the project 'Virtual Simulator of Actions of the Polish Government Protection Office'.

Research limitations/implications: The research is limited to simulators specified in purpose section.

Practical implications: It is anticipated that more accurate selection of individuals for security services will be possible through the use of the proposed research and diagnostic methods and analysis of the results obtained.

Social implications: It is provided that more specific choice of people for security services will result in better training of the staff, an increase of the sense of security of the protected people as well as their quality of life. 
Originality/value: The novelty of the article is an interdisciplinary approach to the study of simulator sickness which takes into account physiological, psychological, social (group work) and technical (type of simulator) aspects.

Keywords: virtual environment, simulator sickness, SSQ questionnaire, psychological test, eye-tracking.

Category of the paper: Conceptual paper.

\section{Introduction}

With the development of flight simulator techniques in the 1980s, motion sickness caused by flight simulators has been observed. This phenomenon has been termed simulator sickness (Johnson, 2005).

Nowadays, virtual environments created by computer simulations are commonly used in learning or training in many different areas that can be divided into four groups. First - medical applications. Duke's Human Simulation and Patient Safety Centre have developed training simulations for physicians in crisis management, procedural skills, decision-making and teamwork. For example, virtual training technologies based on personalized teaching methods have been implemented by Combat Medics to train how to heal wounds which are the leading cause of death on the modern battlefield (Combat Magic, 2017). Postpartum Hemorrhage (PPH) is a $3 \mathrm{D}$ virtual multiplayer platform designed to train clinician teams in the management of postpartum hemorrhage, as well as the development of successful teamwork and interpersonal communication.

Second - military applications. America's Army is a simulation developed by the U.S. Army including recruitment and training (America's Army, 2017). The Chinese Army in turn has released many versions of the FPS Glorious Mission, which has two goals: recruiting soldiers and training staff skills in combat and technological awareness. Other military adaptive training applications focus specifically on medical interventions such as vMedic, which enables one-to-one and multiplayer interactions.

Third - crisis management applications. Zero Hour is a one-person game designed to train the so-called first reaction of medical rescuers in the event of a mass catastrophe such as an earthquake or a terrorist attack. The target groups are pre-school physicians in emergency medical services. In addition to training, the Zero Hour system serves as a recruiting tool for medical rescue (Zero hour, 2017).

Finally, the fourth group - business applications. One of the earliest examples of "gamification" personnel training is Hilton Ultimate Team Play, a customer service training system (Hilton Ultimate Team Play, 2017). Another example is Up Tick!, a system designed to develop sales force that provides adaptive training in real-time tracking student performance data. 
Therefore, using simulators - either in research, selection or training - is inextricably connected with simulator disease. According to Biernacki et al. (2016), it is assumed that simulator sickness occurs when information from all senses that help in orientation in space and perception of motion are in conflict with what has been the subject's prior experience. It is assumed that when an operator performs a task in a new environment (in this case in a simulator), the pattern of traffic information he has performed so far is in conflict with what is presented in the simulator environment. This discrepancy between the present sensory information and what the subject's perceptive system was designed for causes a simulator sickness.

Further Biernacki et al. (2016) suggest that it should be noticed that in the case of selection the phenomenon of simulator sickness may distort the result of the study leading to erroneous conclusions.

On the other hand, in the case of scientific studies the phenomenon of simulator sickness can disturb both the registration of physiological variables and the process of performing the task itself.

Under conditions of training, the simulator sickness can have the opposite effect to the established. This means that its occurrence may interfere with the training process or be a contraindication to the exercise in real conditions. Not without a reason, the recommendation is that the subject after being exposed to these conditions should be stimulated on the same day.

The aforementioned limitations obviously do not negate the development and the need for simulators but rather suggest the control of simulator.

This makes it necessary to study and analyse the symptoms of motion sickness in simulators in order to understand the mechanisms responsible for their development which in turn will minimize the impact of these symptoms on the effects of training / training by optimizing the training/training process itself.

It is important here to make a crucial distinction between the types of simulators. The task of the simulator is to create a virtual environment that primarily acts on visual stimuli. In addition to the way visual presentation is displayed the next factor to consider in simulator sickness research is the type of platform used, with two basic types of platforms: fixed based and motion based. For simulator studies where static platforms are used, traffic information is provided to the tested subject via visual stimuli. Mobile platforms in turn are used to reflect the realism of the study better.

The virtual environment being the subject of the project will in turn be a very specific platform, unlike in the classic simulators in which the user is a single person within the framework of the simulation, the user group (and not the individual user) will be subjected to the learning/training. This entails the fact that each participant in the group will react to both the dynamic changes of the virtual environment and the reactions of the other members of the group. 
This paper consists of the following points: reviewing the literature related to simulator sickness, discussing the impact of the virtual environment on the user's psychophysical state, investigating this impact, summing up and proposing possible studies and analysis related to the simulator users' psychophysical state appearing in the project.

\section{Literature review}

The results of studies on the components of the simulator sickness, its magnitude, correlations with other diseases, causes and treatments have been described in a review at Crowley and Gower (1988). Books edited by McCauley (1984) and Agard (1988) also provide an overview of key research areas. Kennedy's and colleagues' work was concerned with extending simulator sickness analysis using US naval databases (Kennedy, Berbaum, Allgood, Lane, Lilienthal, \& Baltzley, 1988; Kennedy et al., 1987; Kennedy and Frank, 1985; Lilienthal et al. 1987). With the advent of virtual environment technology and nail display technology in the 1990s, the problem of simulator sickness has ceased to concern aeronautical training only and has begun to affect the entertainment industry and its consumers. In later works (Biocca, 1992; Ebenholtz, 1992; Kennedy, \& Fowlkes, 1992; Kennedy, Lane, Lilienthal, Berbaum, \& Hettinger, 1992; Kolasiński, 1995, 1997; Pausch et al, 1992), research related to the issues of disease and virtual reality has not yet been conducted. A detailed review by Wright (1995) addresses the problem of simulator sickness in the training of helicopter pilots.

In summary of literature considerations, it can be said that simulator sickness is a term used to describe the different signs or symptoms experienced by the crew during or after training in a flight simulator. Traffic sickness is in turn a general term for a set of symptoms, generally unfavourable, arising from human exposure to sudden, periodic or unnatural acceleration. Therefore, simulator sickness is a particular case of motion sickness that can be caused by accelerating forces in the simulator or it may also be caused by visual motion without actual motion of the object (McCauley, 1984).

\section{Influence of the virtual environment in the simulator on the psychophysical state of the user}

The simulator sickness is multi-symptomatic (Kennedy, and Fowlkes, 1992; Kennedy, and Frank, 1985; Kennedy, Lane, Berbaum, and Lilienthal, 1993). The symptoms shown by McCauley (1984) are: 
- nausea,

- dizziness,

- spinning sensation,

- flashbacks,

- motor dyskinesia,

- disorientation,

- drowsiness.

In turn, the signs observed by (McCauley, 1984) are:

- pallor,

- cold sweat,

- vomiting.

\section{Examination of the influence of the virtual environment in the simulator on the psychophysical state of the user}

A Simulator Sickness Questionnaire (SSQ) (Kennedy, Lane et al., 1993) was described in 2016 and is being used as a standard test instrument for simulator sickness testing, which attempts to adapt to Polish conditions (Biernacki et al., 2016). This questionnaire lists 16 symptoms:

1. general discomfort,

2. fatigue,

3. headache,

4. eye fatigue,

5. difficulty focusing,

6. increased saliva secretion,

7. sweating,

8. nausea,

9. difficulties with concentration,

10. feeling "fullness of head",

11. blurred vision,

12. imbalance (open eyes),

13. imbalance (closed eyes),

14. dizziness,

15. stomach disorders,

16. bounce (bump). 
In addition, reports of visual retrospective and visual hallucinations have been documented in the work (McCauley, 1984; Wright, 1995; Young, 2003), although they are reported to be extremely rare.

SSQ tests are performed according to a predefined pattern before and after the stay in the simulator, as shown in Appendix A. Based on the results of the study, the level of influence of the simulator on the user is determined, which affects subsequent decisions regarding the use of the simulator, training in the simulator and the length of stay in the simulator.

Some symptoms of simulator sickness can be measured objectively using techniques called eye tracking.

Eye tracking is a method that allows you to track eye movements and determine the location of the eye focus, the detection of the pupil movements, the pupil microscope and the frequency and duration of blinking.

In the paper (Liossi et al., 2014), the authors examine the perception of images by people with chronic daily headache. Studies show that people with headaches pay attention to other details in the picture and prefer to watch images that are less associated with pain. This is the basis for reverse studies, in which showing a collection of images to a person and checking their reactions is an estimate of whether a person is prone to headaches.

In fact, research conducted within Iatsun et al. (2013) focuses more on the occurrence of abnormalities in the use of 3D extended reality equipment. The results of the conducted tests show that visual fatigue can be detected basing on the blink time and saccade measurements.

The study of eye movements is one of the basic investigations in the diagnosis of cerebral shock and structural brain damage. The authors (Samadani et al., 2015) present a method based on the tracking of non-rotating ocular movements in patients who are shown a short movie.

The most common use of eye tracking is the detection of fatigue, especially in drivers. There are many publications in the subject matter (examples: Horng et al., 2004, Devi et al., 2008, Eriksson, and Papanikotopoulos, 1997). The blink time or shutter speed is generally measured.

It is difficult to find the correlation between salivary hyperacidity and eye movements, but there are cases where unusual eye movements and excessive salivation are the result of one disorder. This is the case, for example, in the diagnosis of ADHD, FADS and PD (Tseng et al., 2013). It is similar to the phenomenon of excessive sweat secretion (Kang et al., 2012). 


\section{5. $M A N-M A N-M A C H I N E$ interaction in the simulator}

The virtual environment in the simulator causes the so-called simulator sickness, well known and described in literature. Analysis of the effects of the disease on the users of a given simulator may allow one to propose a procedure to use the simulator to minimize or control the symptoms of the simulator sickness.

As mentioned in the introduction, the virtual environment being the subject of the project will be a very specific platform, because unlike the classic simulators in which one person is a user within the framework of the simulations, a user group (and not an individual user) will be subjected to learning/training. The visualisation of the simulator is presented in fig. 1 . The size of the simulator is about 25 meters in diameter, the length of the screen is about 70 meters and the height is about 3.5 meters.

This entails the fact that each participant in the group will react to both the dynamic changes of the virtual environment and the reactions of the other members of the group. The analysis of this type of reaction goes beyond man-machine-type (computer) interaction analysis and is actually a human-human-machine interaction.

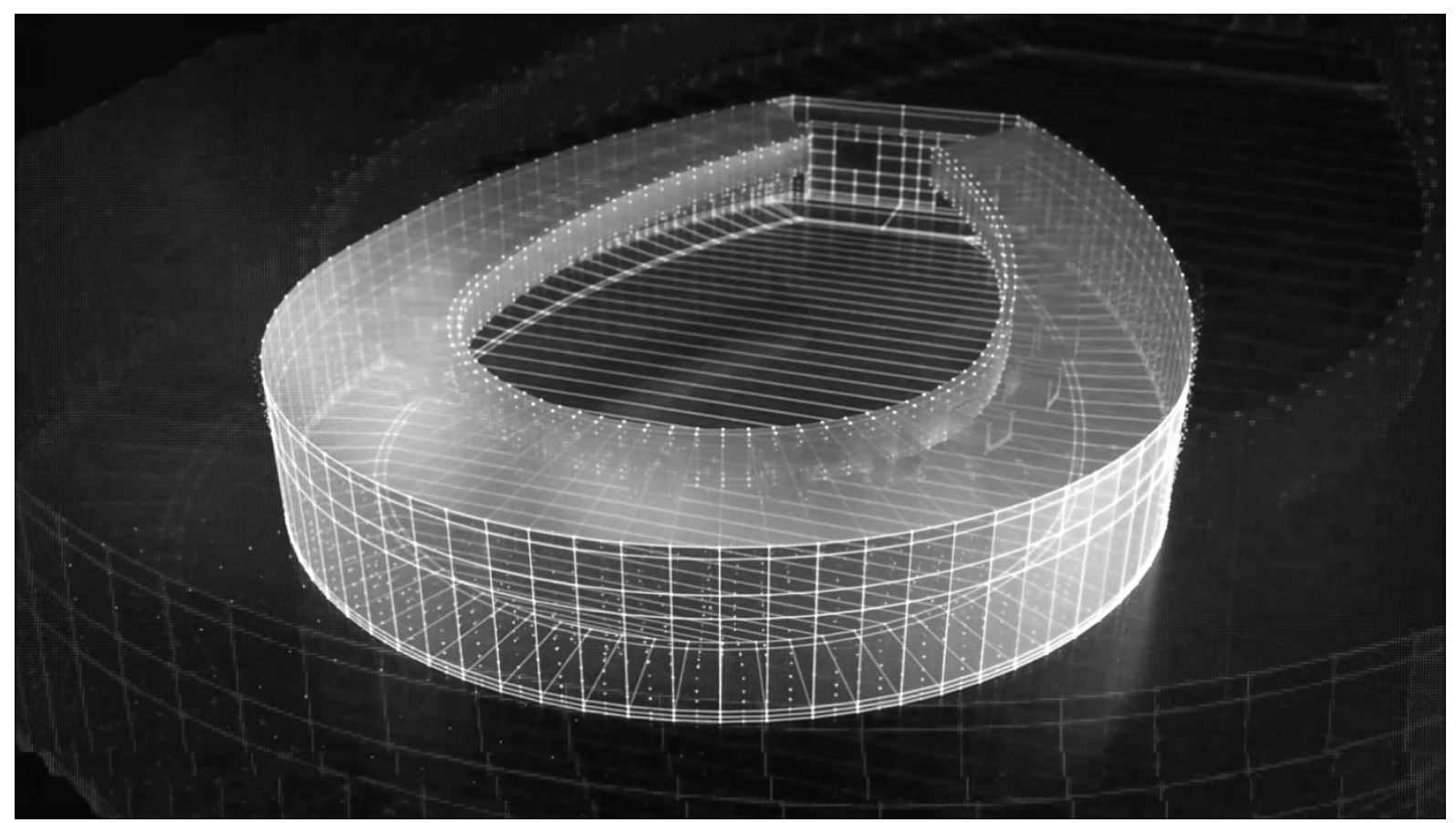

Figure 1. The visualisation of the simulator.

In addition, the platform's design combines the features of a static and dynamic platform. While scenarios in the simulator are displayed in a manner that is specific to the static platform, the simulator user group has no motion constraints and can introduce virtual dynamic elements for themselves (e.g. cars) into the virtual environment, what is presented on exemplary scenario in fig. 2. 


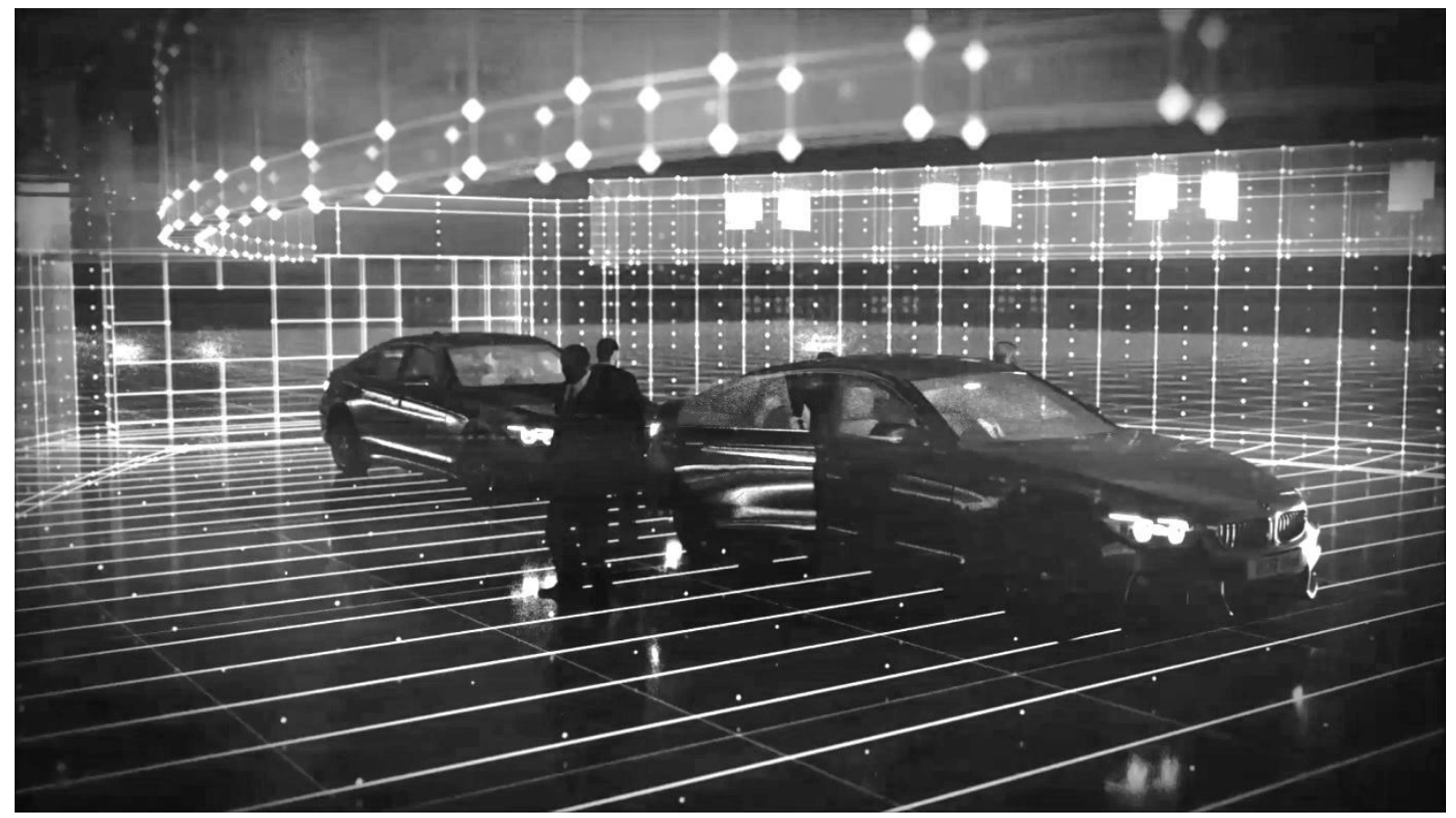

Figure 2. The visualisation of the exemplary scenario.

This results in a complex simulator structure that combines both static and dynamic simulation platform elements, as well as the real and virtual environments that the user group interacts with.

The effect of such complex simulation environment on the user's psychophysical state may go beyond the framework described in the literature. This implies that, in addition to classical studies on the influence of the virtual environment on the psychophysical state (symptoms of the simulator sickness), the effects of human-human-machine interactions and interpersonal interactions should also be included in the study.

\section{Proposals for possible studies and analyses related to the simulator users' psychophysical state appearing in the project}

The complex configuration of the target simulation environment causes its effect on the user's psychophysical state to go beyond the framework described in the literature. This implies that, in addition to classical studies on the influence of the virtual environment on the psychophysical state (symptoms of the simulator sickness), the effects of human-humanmachine interactions and interpersonal interactions should also be included in the study.

It is proposed to conduct a study on the impact of the virtual environment on psychophysical factors of the user based on Table 1. The last column of Table 1 distinguishes the types of interaction studied. In Type A, the classic man-machine interaction was adopted, whereas in Type B - man-man-machine - refers to the complex interaction resulting from the fact that 
a member of a group in a simulator interacts with both the virtual environment and the real elements, which are also dynamically changing, i.e. other members of the group, vehicles, etc. As it is indicated in Table 1 it is proposed to extend the set of classical tests with three psychological tests: CISS, COPE and STAI. This proposal is a result of a specific configuration of virtual environment.

The Coping Inventory of Stressful Situations - CISS (Endler et al., 1990) is a questionnaire for diagnosing stress management styles. It consists of 48 statements about the different behaviours people can take in stressful situations. The examined person determines on a 5-point scale the frequency of the activity undertaken in difficult stressful situations.

COPE Inventory (Carver et al., 1989) is a questionnaire used to assess how to deal with stress. This is a self-report tool consisting of 60 statements, which correspond to a 4-step scale. It allows you to evaluate 15 strategies to cope with stressful situations.

Table 1.

Psychophysical factors and tools for their examination

\begin{tabular}{|c|c|c|c|}
\hline No & Psychophysical factor & Test tool & $\begin{array}{c}\text { Type of } \\
\text { interaction }\end{array}$ \\
\hline 1 & Nausea & Simulator Sickness Questionnaire (SSQ) - Polish version & A \\
\hline 2 & Oculomotor disturbances & Simulator Sickness Questionnaire (SSQ) - Polish version & $\mathrm{A}$ \\
\hline 3 & Disorientation & Simulator Sickness Questionnaire (SSQ) - Polish version & $\mathrm{A}$ \\
\hline 4 & $\begin{array}{l}\text { Balance disorders } \\
\text { (eyes closed, eyes open) }\end{array}$ & $\begin{array}{l}\text { Standing on Preferred Leg (SOPL) test, e.g. (Fowlkes and } \\
\text { Kennedy 1987) } \\
\text { Standing on the Non-Preferred Leg (SONL) test, e.g. } \\
\text { (Fowlkes and Kennedy 1987) }\end{array}$ & A \\
\hline 5 & Divisibility of attention & Poppelreuter boards, Eye-tracking techniques & $\mathrm{A}, \mathrm{B}$ \\
\hline 6 & Coping with stress & $\begin{array}{l}\text { Coping Inventory of Stressful Situations (CISS) - Polish } \\
\text { version } \\
\text { COPE Inventory - Polish version }\end{array}$ & $\mathrm{A}, \mathrm{B}$ \\
\hline 7 & $\begin{array}{l}\text { Fear as a condition and } \\
\text { as a feature }\end{array}$ & The State-Trait Anxiety Inventory (STAI) - Polish version & $\mathrm{B}$ \\
\hline 8 & Eye fatigue & Eye tracking techniques & A \\
\hline 9 & Difficulties with focusing & Eye tracking techniques & $\mathrm{A}$ \\
\hline
\end{tabular}

NOTE: Type A - the classic man-machine interaction; Type B - man-man-machine interaction (a new approach).

Finally, the State-Trait Anxiety Inventory - STAI (Spielberger et al., 1983) is a tool designed to study anxiety understood as a transient and conditioned state of an individual and an anxiety understood as a relatively constant personality trait. STAI consists of two sub-scales, one of them (X-1) serves to measure anxiety-state and the other (X-2) - anxiety-trait.

Tests should be analysed by psychologists using Polish versions of the tests and appropriate scoring tools.

All tests must be conducted before and after the stay in the simulator (pre-test analysis dependent test), except for the X-2 part of STAI test. In order for the results to be significant, it is recommended that the group of subjects consists of at least 30 people. 


\section{Acknowledgements}

Work partly financed from Silesian University of Technology BK Grant 02/010/BK18/0102 (BK/200/Rau1/2018) for the first author, Katowice School of Economics statutory funds in 2019 for the second author, AIDA Doctorate funds in 2019 for the third author and the National Centre for Research and Development grant DOB-BIO6/11/90/2014 in the year 2019 for the fourth author.

\section{References}

1. AGARD (1988). Motion cues in flight simulation and simulator induced sickness (AGARD Conference Proceedings, No. 433). Neuilly Sur Seine, France: Advisory Group for Aerospace Research and Development.

2. America's Army (2017). https://www.americasarmy.com/. 2.05.2017.

3. Biernacki, M.P., Kennedy, R.S., Dziuda, Ł. (2016). Zjawisko choroby symulatorowej oraz jej pomiar na przykładzie kwestionariusza do badania choroby symulatorowej - SSQ. Medycyna Pracy, 67(4), 545-555.

4. Biocca, F. (1992). Will simulation sickness slow down the diffusion of virtual environment technology? Presence, 1(3), 334-343.

5. Carver, C.S., Scheier, M.F., Weintraub, J.K. (1989). Assessing coping strategies: a theoretically based approach. Journal of Personality and Social Psychology, Feb., 56(2), 267-83.

6. Combat magic (2017). Duke Human Simulation and Patient Safety Center. http://anesthesiology.duke.edu/?page_id=825637. 28.05.2017.

7. Commercial/Hilton-Ultimate-Team-Play. Access 2.05.2017.

8. Crowley, J.S., \& Gower, D.W. (1988). Simulator sickness. US Army Aviation Digest, 1-88-11, 9-11.

9. Devi, Mandalapu Sarada, and Preeti, R., Bajaj (2008). Driver fatigue detection based on eye tracking. First International Conference on Emerging Trends in Engineering and Technology. IEEE.

10. Endler, N.S., Parker, J.D.A. (1990). Multidimensional Assessment of Coping: A Critical Evaluation. Journal of Personality and Social Psychology, 58(5), 844-854.

11. Eriksson, M., and Papanikotopoulos, N.P. (1997). Eye-tracking for detection of driver fatigue. Intelligent Transportation System, ITSC'97, IEEE Conference.

12. Fowlkes, J.E., Kennedy, R.S. (1987). Postural disequilibrium following training flights. Proceedings of the human factors society - 31st annual meeting. 
13. Hilton Ultimate Team Play (2017). http://www.virtualheroes.com/portfolio/.

14. Horng, Wen-Bing, et al. (2004). Driver fatigue detection based on eye tracking and dynamk, template matching. Networking, Sensing and Control, IEEE International Conference, 1.

15. Iatsun, Iana; Mohamed-Chaker, Larabi; Christine, Fernandez-Maloigne (2013). Investigation of visual fatigue/discomfort generated by S3D video using eye-tracking data. Proc. SPIE 8648, Stereoscopic Displays and Applications, XXIV, 864803 (March 12, 2013); doi:10.1117/12.2008206.

16. Johnson, D.M. (2005). Introduction to and Review of Simulator Sickness Research. U.S. Army Research Institute for the Behavioral and Social Sciences, Research Report, 1832.

17. Kalejta, T. (2016). Test tablic Poppelreutera. http://unipar.pl/aparaty/test-tablicpoppelreutera, 2.01.2016.

18. Kang, O-Seok, et al. (2012). Individual differences in smoking-related cue reactivity in smokers: an eye-tracking and fMRI study. Progress in Neuro-Psychopharmacology and Biological Psychiatry, 38.2, 285-293.

19. Kennedy, R.S., Berbaum, K.S., \& Lilienthal, M.G. (1997). Disorientation and postural ataxia following flight simulation. Aviation, Space, and Environmental Medicine, 68, 13-17.

20. Kennedy, R.S., Berbaum, K.S., Allgood, G.O., Lane, N.E., Lilienthal, M.G., \& Baltzley, D.R. (1988). Etiological significance of equipment features and pilot history in simulator sickness. In: AGARD, Motion cues in flight simulation and simulator induced sickness (AGARD Conference Proceedings, 433, pp. 1.1-1.22). Neuilly Sur Seine, France: Advisory Group for Aerospace Research and Development.

21. Kennedy, R.S., Berbaum, K.S., Lilienthal, M.G., Dunlap, W.P., Mulligan, B.E., \& Funaro, J.F. (1987). Guidelines for alleviation of simulator sickness symptomatology (NAVTRASYSCEN TR-87-007). Orlando, FL: Naval Training Systems Center.

22. Kennedy, R.S., Lane, N.E., Berbaum, K.S., \& Lilienthal, M.G. (1993). Simulator Sickness Questionnaire: An enhanced method for quantifying simulator sickness. International Journal of Aviation Psychology, 3(3), 203-220.

23. Liossi, C., Schoth, D.E., Godwin, H.J., Liversedge, S.P. (2014). Using eye movements to investigate selective attention in chronic daily headache, $P A I N \circledast$, 155, 3, ISSN 0304-3959, http://dx.doi.org/10.1016/j.pain.2013.11.014.

24. McCauley, M.E. (Ed.). (1984). Research issues in simulator sickness: Proceedings of a workshop. Washington, D.C.: National Academy Press.

25. Pausch, R., Crea, T., \& Conway, M. (1992). A literature survey for virtual environments: Military flight simulator visual systems and simulator sickness. Presence, 1(3), 344-363.

26. Samadani, Uzma, et al. (2015). Eye tracking detects disconjugate eye movements associated with structural traumatic brain injury and concussion. Journal of Neurotrauma, $32.8,548-556$. 
27. Spielberger, C.D., Gorsuch, R.L., Lushene, R., Vagg, P.R., \& Jacobs, G.A. (1983). Manual for the State-Trait Anxiety Inventory. Palo Alto, CA: Consulting Psychologists Press.

28. Tseng, Po-He, et al. (2013). High-throughput classification of clinical populations from natural viewing eye movements. Journal of Neurology, 260.1, 275-284.

29. Wright, R.H. (1995). Helicopter simulator sickness: A state-of-the-art review of its incidence, causes, and treatment (ARI Res. Rep. 1680). Alexandria, VA: U.S. Army Research Institute for the Behavioral and Social Sciences.

30. Young, L.R. (2003). Spatial orientation. In: P.S. Tsang \& M.A. Vidulich (Eds.), Principles and practice of aviation psychology (pp. 69-113). Mahwah, NJ: Erlbaum.

31. Zero hour (2017). http://www.virtualheroes.com/portfolio/Government/Zero-Hour-America---s-Medic. 5.01.2019. 